\title{
A Survey of Health Management User Objectives in Aerospace Systems Related to Diagnostic and Prognostic Metrics
}

\author{
Kevin R. Wheeler ${ }^{1}$, Tolga Kurtoglu ${ }^{2}$, and Scott D. Poll ${ }^{1}$ \\ ${ }^{1}$ NASA Ames Research Center, Moffett Field, CA, 94035, USA \\ kevin.r.wheeler@nasa.gov \\ scott.d.poll@nasa.gov \\ ${ }^{2}$ Palo Alto Research Center, Palo Alto, CA, 94304, USA \\ kurtoglu@parc.com
}

\begin{abstract}
One of the most prominent technical challenges to effective deployment of health management systems is the vast difference in user objectives with respect to engineering development. In this paper, a detailed survey on the objectives of different users of health management systems is presented. These user objectives are then mapped to the metrics typically encountered in the development and testing of two main systems health management functions: diagnosis and prognosis. Using this mapping, the gaps between user goals and the metrics associated with diagnostics and prognostics are identified and presented with a collection of lessons learned from previous studies that include both industrial and military aerospace applications.
\end{abstract}

\section{INTRODUCTION}

One of the possible reasons for slow adoption of integrated health management systems is the vast difference in user objectives with respect to engineering development. In this paper, we present a survey of the objectives of different users of integrated health management systems, how they each would measure success of such systems (metrics), and how these objectives and metrics relate to engineering efforts developing prognostic and diagnostic algorithms and systems. These user objectives and

This is an open-access article distributed under the terms of the Creative Commons Attribution 3.0 United States License, which permits unrestricted use, distribution, and reproduction in any medium, provided the original author and source are credited.

Submitted 3/2010; Published 10/2010 associated metrics are identified across operational, regulatory and engineering domains for both industrial and military aerospace applications.

This survey was sponsored by NASA's Aviation Safety Program, Integrated Vehicle Health Management (IVHM) Project to aid in identifying critical gaps within their existing research portfolio that are not currently being addressed by the broader research community.

\section{ORGANIZATION}

The rest of the paper is organized as follows: Section III gives background on the application of health management in the aviation domain; Section IV discusses the motivation and competing challenges for health management; Section V presents objectives and metrics for different health management users; Section VI describes metrics associated with development and operation of diagnostic and prognostic systems; finally, sections VII and VIII provide discussion and summary, respectively, of the topics in this paper.

\section{BACKGROUND}

The first generation aircraft health management system (as exemplified in B727, DC-9/MD-80, B737 classic) consisted of "push-to-test" functionality of mechanical and analog systems in which a button was pressed to test internal circuitry and simple status lights would illuminate the go/nogo results for the device under test. The second generation (B757/767, B737NG, MD-90, A320) saw the use of black-box digital systems to carry out the health management functions previously performed by mechanical and analog systems. The third generation (MD-11, B747-400) saw the introduction of systems implementing the ARINC Standard 604, "Guidance for Design and Use of 
Built-In Test Equipment.” Early third generation systems allowed centralized access to the federated avionics BIT results but required manual consolidation of Line Replaceable Unit (LRU) fault indications. Later third generation systems used Central Maintenance Computers to aggregate all fault indications and perform root cause analysis via complex logic-based equations. The ability to downlink fault results to ground stations while en route was also added. Lessons learned were incorporated into updated standards, including ARINC 624, "Design Guidance for Onboard Maintenance System." The fourth generation implements improved health management functionality through the use of modular avionics. In contrast to having specific avionics functions associated with a LRU, multiple avionics functions are associated with Line Replaceable Modules. The health management system employed on the Boeing 777 represents the fourth generation in the evolution of vehicle health management (Honeywell, 2007). The Boeing 777 Airplane Information Management System integrates two key diagnostic subsystems: the Central Maintenance Computing Function, which diagnoses faults after they happen, and the Airplane Condition Monitoring Function, which collects data to allow prediction of future problems and thus enables condition-based maintenance. In contrast to the logic equation-based diagnostics in previous health management systems, the central maintenance control system in the Boeing 777 employs model-based reasoning in an attempt to overcome difficulties in developing and maintaining the health management functions. Subsequent developments have extended the scalability and extensibility of the modular avionics systems and the associated health management functionality. Despite the advances over the years, there are still difficulties in developing and implementing health management systems that meet user requirements (Scandura, 2005), although these difficulties may be more programmatic than technical.

MacConnell (2007) conducted an extensive working group study on the benefits of ISHM consisting of representatives from the Air Force Research Laboratory (AFRL), Boeing, General Electric, Honeywell, Lockheed Martin, Northrop Grumman, United Technologies, and others. New benefits were identified that may be perceived as more indirect. For example, automated monitoring could be relied on to dramatically reduce factors of safety for design and to enable revolutionary certification processes. The working group (MacConnell, 2007) ranked the relative importance of the functional areas in ISHM benefits. The top five were diagnostics, analysis, design, structure and propulsion. This is a mix of health management functions (diagnostics, analysis) with application areas (structure, propulsion). This highlights that the words used (ontology) amongst even a group of experts can cause opacity in health management discussions thus making it difficult to clearly outline the requirements driving the development and integration of fleet wide health management systems.

Ofstun (2002) has a succinct overview of developing IVHM for aerospace platforms, pointing out that traditional built-in-tests generally have not provided the accuracy or reliability needed to impact operational efficiency and maintenance. A goal of IVHM should be to both improve and extend traditional BIT approaches in subsystems such as avionics, electrical (including wiring), actuators, environmental control, propulsion, hydraulics, structures as well as overall system performance.

Ofsthun (2002) highlights IVHM lessons learned that are points similar to those that will be seen in this article relating user community goals to diagnostic and prognostic modeling metrics. Our article highlights:

IVHM performance measures need to be derived by an integrated product development team that accounts for all expected user groups.

- Cost/benefit analyses need to be conducted for each expected user group during requirements definition.

- A common health management infrastructure is needed to integrate across subsystems - including definition of subsystem responsibilities.

- Trade-space analyses need to be conducted between failure detection and false alarm rates including crew enabled filtering.

- Verification and validation of IVHM system needs to include incremental validation by demonstrations as well as opportunistic monitoring.

Currently the best developing example of a highly integrated system for health management is the Joint Strike Fighter program (JSF) which mandates such a development (Hess et al., 2004). One of the greatest challenges in developing a health management system from the ground up has been in refining the user objectives and requirements to an adequate level that includes buy-in from the expected and varied user groups.

The following section outlines general (nonformatting) guidelines to follow. These guidelines are applicable to all authors and include information on the policies and practices relevant to the publication of your manuscript.

\section{MOTIVATION}

Wide-spread adoption of integrated health management has been slow due to competing factors that have to be satisfied within the HM user community. Two areas stand out in this regard: Aging and Expected Life and Cost vs. Benefit.

\subsection{Aging and Expected Life}

As the average age of air fleets begins to be higher than the original expected useful life, in order to preserve safety-of-flight, it becomes necessary to increase the periodicity and depth of inspections. 
This results in an increase in maintenance costs as well as longer periods of downtime. One of the benefits of an ISHM system that includes structural health monitoring is that this inspection burden can be reduced by relying upon continuous monitoring (Albert et al., 2006). The USAF has deployed structural monitoring systems that allow for the required maintenance inspection interval to be tailored to each aircraft, which has resulted in reducing the inspection burden, costs and amount of downtime.

One might be tempted to suggest that if the average age of an air fleet (either military or commercial) is starting to exceed the expected life, then a possible strategy to reduce the average age would be to begin replacement of the oldest with new aircraft. Unfortunately, especially in the case of the U.S. DoD, with given budgets it would not be possible to decrease the average age enough to make a difference. This is also true in civilian fleets: "The statistics show that the number of aging aircraft (older than 15 years) has increased continuously. This number was around 4600 in 1997 for US and European built civil aircraft flown with more than 1900 aircraft older than 25 years. This number increased to 4730 ( $>15$ years) and 2130 (>25 years) respectively in 1999” (Boller, 2001).

From an engineering perspective, the development of health management systems design to mitigate the greatest risks is dependent upon accurate data collection. The data needed for maturation analysis is usually difficult both to obtain (due to heterogeneous systems) as well as to collect: "- this makes access, retrieval, and integration of the requisite information a costly and often incomplete process at best" (Wilmering, 2003).

\subsection{Cost vs. Benefit}

Installation of integrated health management systems incur development, installation and life cycle costs. Some of the costs associated with a health management solution include maintenance of the health management system components (such as sensor replacement and software upgrades) as well as increases in system volume and mass requirements. These costs need to be countered with expected savings gains over the life of the aircraft through a rigorous cost benefit analysis (CBA). The slow acceptance of health management tools has been attributed to the incomplete total life cycle systems engineering management (Millar, 2007) which introduces an approach for proper system analysis methods. Often the optimization of objectives consists of conflicting goals such as minimizing purchase cost and maximizing availability (Yukish et al., 2001). Calculating costs such as operating costs consists of complex parameters such as average downtime for unplanned repairs.

In spite of these challenges, different methods have been developed to analyze cost-benefit tradeoffs for designing and implementing IVHM systems. For example, [20] discusses the benefits of IVHM to five different categories of operators: the Original Equipment Manufacturers (OEMs), the mission operators, command/control elements, fleet management, and maintenance operators. These five categories may overlap in organizational structure and personnel, but they have clearly identifiable processes and performance that can be measured. Another example of an approach to conducting a CBA for IVHM appears in (Ashby and Byer, 2002). Their methodology utilizes pre-existing reliability and logistics source information from a Failure Modes and Effects Criticality Analysis (FMECA), line maintenance activities and legacy field event rates. IVHM will have the greatest benefit when it is applied to those areas that are historically the least reliable, have failure modes that can greatly impact mission success, have sub-systems that are the most difficult to diagnose or for which replacements parts cannot be obtained in a timely-manner (Banks et al., 2005).

The impacts of diagnostic capability on unscheduled maintenance include (Ashby and Byer, 2002):

- reduction of cannot duplicate rates

- reduction of labor mean-time-to-detect (MTTD)

- reduction of line replaceable unit (LRU) repair costs

- reduction of repair times (increase availability)

The benefits impacting scheduled maintenance include:

- reduction of labor

- reduction of maintenance induced failures

- elimination of scheduled maintenance

Prognostic capabilities impacting operations include:

- reduction in number of engine in-flight shutdowns, mission aborts, lost sorties

- reduction of secondary damage

- ability to reconfigure and re-plan for optimal usage of the remaining useful life (RUL) of failing components

- maximized usage of the component life while ensuring mission safety

One example of cost-benefit quantification of ISHM in aerospace systems appears in (Hoyle et al., 2007). Their methodology analyzes the trade-offs between system availability, cost of detection, and cost of risk. In this optimization formulation, cost of detection includes the cost of periodic inspection/maintenance and the cost of ISHM; cost of risk quantifies risk in financial terms as a function of the consequential cost of a fault and the probabilities of occurrence and detection. Increasing 
the ISHM footprint will generally lower cost of risk while raising cost of detection, while availability will increase or decrease based upon the balance of the reliability and detection capability of the sensors added, versus their ability to reduce total maintenance time.

The business case for ISHM generated by an ISHM working group composed mostly of industry (MacConnell, 2007) resulted in the following rankings of benefits:

\section{Maintenance time savings}

2. False alarm avoidance - reduce can not duplicate (CND) and retest okay (RTOK)

3. Availability Improvement - increase MTBMA - mean time between maintenance actions

\section{Spares and supply savings \\ 5. Recurring cost savings.}

In the past, there have been many anecdotal accounts of the benefits of ISHM. Now some systems, such as the condition based maintenance helicopter programs are starting to produce real results. For example in (Nenniger, 2007) implementing health management in the UH-60 has resulted in an increase in fully mission capable status from $65 \%$ to $87 \%$ resulting in an increase in total flight hours from 10,331 to 21,819 .

There are uncertainties inherent to new Prognostics and Health Management (PHM) systems such as the fact that not all faults will be diagnosed correctly (PHM Effectiveness). Two factors that may detract from the benefits of prognostics (Hecht, 2006):

- Prognostics may cause some sub-systems to be replaced much earlier than their eventual failure thus reducing their useful life. This will require engineering resources to analyze replaced units in order to optimize replacement thresholds.

- False prognostic replacement indicators may cause replaceable units to be replaced that are not in any danger of failing. This will require further engineering resources to mitigate these false alarms.

The perceived and real difficulties of retrofitting legacy aviation systems with effective health management and the challenges of unambiguously quantifying the benefit in new systems has hampered more wide-spread adoption of integrated health management. However, more and more, these technical and programmatic issues are being addressed within the health management community.

\section{USER OBJECTIVES AND METRICS}

In order to present the ISHM user objectives and metrics we have chosen to broadly categorize types of users. There are many different ways to categorize these health management stakeholders. Our approach is shown in Figure 1.

Our three top-level stakeholder categories are Operations, Regulatory and Engineering. In this paper, we focus on looking at the user objectives derived from operations and how these impact the modeling efforts of the engineering activities.

The three distinct user groups consist of operations, regulatory and engineering. Within operations we have logistics, flight, maintenance, fleet management and training. Regulatory users are concerned mainly with establishing FAA amendments and new rules taking advantage of health management information. Within engineering we have sustaining, $R \& D$ and manufacturing. Although design engineers can be considered users of health management, due to space considerations we do not survey engineering design.

In the remainder of this article we have chosen to highlight each identified user objective only once even if it may be attributable to multiple users. For example, reducing labor is an objective that spans multiple users but the associated user metric is universal - hours of labor. Our categorization also has forced boundaries between user groups that may cause some of the objectives to be split. For example, one of the user objectives for logistics is to reduce the mean time to repair. We have chosen to put this under logistics rather than under maintenance as in (Hess et al., 2005).

\section{HM Objectives}

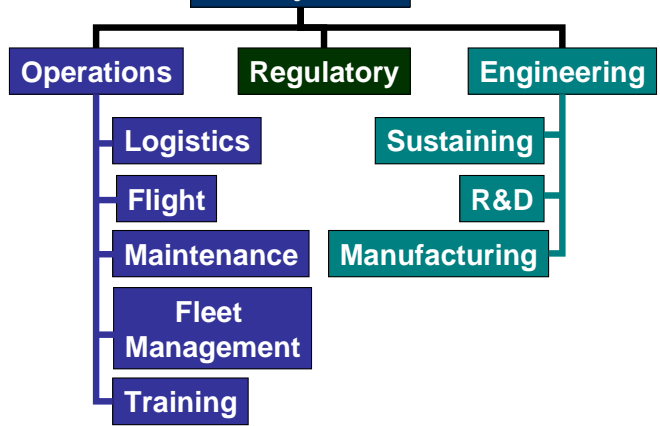

Figure 1. Categorization of groups driving health management objectives. 
Table 1. Logistics HM Goals and Metrics (d: diagnostics, p: prognostics)

\begin{tabular}{|c|c|c|}
\hline Logistics Goals & User Metrics & Map \\
\hline $\begin{array}{l}\text { L.1 Reduce repair turn- } \\
\text { around time }\end{array}$ & $\begin{array}{l}\text { Mean time to } \\
\text { repair (MTTR), } \\
\text { time delays } \\
\text { waiting for parts }\end{array}$ & $\mathrm{d}, \mathrm{p}$ \\
\hline $\begin{array}{l}\text { L. } 2 \text { Reduce ground } \\
\text { support equipment and } \\
\text { personnel }\end{array}$ & $\begin{array}{l}\text { Equipment value, } \\
\text { volume, weight } \\
\text { and number of } \\
\text { personnel }\end{array}$ & d \\
\hline $\begin{array}{l}\text { L. } 3 \text { Increase } \\
\text { availability/decrease } \\
\text { unscheduled } \\
\text { maintenance }\end{array}$ & $\begin{array}{l}\text { Mean time in } \\
\text { service }\end{array}$ & $\mathrm{p}$ \\
\hline L.4 Reduce labor & Labor-hours & $\mathrm{d}, \mathrm{p}$ \\
\hline $\begin{array}{l}\text { L. } 5 \text { Reduce periodic } \\
\text { inspections }\end{array}$ & $\begin{array}{l}\text { Frequency of } \\
\text { periodic } \\
\text { inspections }\end{array}$ & $\mathrm{p}$ \\
\hline $\begin{array}{l}\text { L. } 6 \text { Predict remaining } \\
\text { useful life in } \\
\text { components, maximize } \\
\text { component life usage } \\
\text { and tracking }\end{array}$ & $\begin{array}{l}\text { Accuracy in } \\
\text { prediction, } \\
\text { minimize false } \\
\text { alarms }\end{array}$ & $\mathrm{p}$ \\
\hline $\begin{array}{l}\text { L. } 7 \text { CBM - Schedule } \\
\text { regular maintenance } \\
\text { only as necessary - } \\
\text { Predict remaining } \\
\text { useful life in } \\
\text { expendables (e.g. oil) }\end{array}$ & $\begin{array}{l}\text { Prediction } \\
\text { accuracy }\end{array}$ & $\mathrm{p}$ \\
\hline $\begin{array}{l}\text { L. } 8 \text { Ease of using entire } \\
\text { information system }\end{array}$ & $\begin{array}{l}\text { Measure of } \\
\text { integration and } \\
\text { information access: } \\
\text { data access, } \\
\text { security, search, } \\
\text { increase IS } \\
\text { availability, } \\
\text { decrease costs... }\end{array}$ & $\mathrm{d}, \mathrm{p}$ \\
\hline $\begin{array}{l}\text { L. } 9 \text { Increase surge } \\
\text { capacities }\end{array}$ & Surge capacity & $\mathrm{d}, \mathrm{p}$ \\
\hline $\begin{array}{l}\text { L. } 10 \text { Reduce costs of } \\
\text { reconfigurations and } \\
\text { turn-arounds }\end{array}$ & $\begin{array}{l}\text { Total \$ spent on } \\
\text { reconfigurations }\end{array}$ & $\mathrm{d}, \mathrm{p}$ \\
\hline $\begin{array}{l}\text { L.11 Maximize vendor } \\
\text { lead time }\end{array}$ & Lead time & $\mathrm{p}$ \\
\hline L.12 Inventory & Spare parts usage & $\mathrm{d}, \mathrm{p}$ \\
\hline
\end{tabular}

\subsection{Logistics}

DEFINITION: Logistics is the science of planning and executing the acquisition, movement and maintenance of resources necessary to sustain aeronautical operations.

The bottom line for logistics is to make operations faster, cheaper (less stuff, less personnel) and more consistent and reliable (less uncertainty and more predictable). This top floor view of logistics can be translated into the user objectives and associated metrics listed in Table 1. All of the user objectives tables presented will have the rightmost column indicating whether the performance metric can be mapped into diagnostics (d), prognostics (p), both or neither.

In this table are objectives that would exist even without any health management solution such as reducing turn-around and repair times. Hopefully, these can be improved through the appropriate application of health management information. The issue of reducing ground support also exists whether or not we have a health management system. The central concept is that the diagnostic (fault type and location) information available will reduce the need for extensive ground test equipment and will reduce the time spent on facilitating repairs as well.

Reducing the frequency of periodic inspections by relying upon more extensive system monitoring is starting to become a reality in the Air Force [16]. The individual aircraft tracking program enables the development of an individualized aircraft specific maintenance schedule (including inspections) based on actual fatigue loads and/or crack lengths for each aircraft.

Without IVHM, consumables (such as oil) are replaced at a fixed schedule based upon expected usage. Condition based maintenance (CBM) [6, 7] has started using the operating regime to modify this replacement schedule and the inspection intervals. Heavy use will result in more frequent inspections and vice versa. Additionally, the actual condition of the consumable/expendable can be monitored either directly or indirectly based upon operating conditions. The rate of deterioration can be estimated and then the optimal replacement schedule predicted so that the operator can be notified in advance. This type of technology enables logistics to schedule service in advance at an optimal replacement schedule.

A final point on logistics is the user objective for ease of use of the entire information system (IS). This includes ensuring that the appropriate people/teams have access to the appropriate information at the right time with sufficient data integrity and security. Unfortunately, many times the information system is thought of after the fact as merely a way to archive records. This lack of 
integration has been identified as a large reason for failure (Hess and Fila, 2002). It should be noted that measuring "ease of use" for an entire IS is very difficult and subject to multiple, sometimes conflicting ideologies. Many measures associated with evaluating the usability of an enterprise system are subjective.

The Air Force has set the objective of modernizing the information systems that underlie its logistics with the goal to increase IS equipment availability by $20 \%$ and reduce annual operational expenses by $10 \%$ (Alford, 2007).

The objectives and metrics associated with an information system that spans all aspects of aviation operations are far beyond the scope of this article. However, we will highlight some of the key aspects with respect to health management and how a user might assess:

$$
\begin{aligned}
& \text { - asset tracking } \\
& \text { - individual aircraft condition assessment } \\
& \text { - demand management } \\
& \text { - lifecycle product management } \\
& \text { - integrated planning system } \\
& \text { - purchasing supply chain management } \\
& \text { - fleet decision management tools }
\end{aligned}
$$

The Joint Strike Fighter program is developing autonomic logistics information system tools to integrate management systems (e.g. fleet and maintenance) along with knowledge discovery tools and anomaly and failure resolution systems. Since the IS is responsible for enabling real-time information flow between maintenance, training, supply and mission planners as well as to provide data for performance analytics it can be considered the backbone of logistics (Byer et al., 2001).

In the past, such large scale integrated IS implementations have failed for a number of reasons such as poor understanding of the requirements, immature products, limited testing in actual environments and under appreciating and under valuing the effort required for data cleanup (Alford, 2007). Typically data useful for analytical modeling is contained in multiple heterogeneous systems. (Wilmering, 2003)

One difficulty of accurate maintenance data collection is more than just an information system issue - humans are the ones performing the maintenance actions and entering the maintenance data into the information system. In the past, the maintenance codes provided to maintenance technicians in both military and civilian sectors were rather coarse grained to enable easier entry during maintenance. This meant that during unscheduled maintenance debugging activities, there could be inaccuracies generated either from entering the closest (or most familiar) maintenance code or entering the wrong premature diagnosis. For example, electrical wiring in the past was not considered as a separate system but rather was just the thing between reportable subsystems. This meant that wiring problems were often under reported within the maintenance database. This has been addressed by adding additional maintenance codes and making the definitions more precise with the adverse consequences of requiring even more labor and costing more time for maintenance technicians.

Another aspect to ensuring the utility of the information system is through the use of common architectures, interoperability metrics, common standards and a clear path to implementation [29]. The U.S. Department of Defense (DoD) Architectural Framework (DoDAF) defines a standard way to organize an enterprise architecture into consistent views (DOD, 2007). Other approaches include ontological interchange standards KIF (KIF, 1998), product data oriented standards such as STEP (S. 1030-1, 1994), and even more specific diagnostic information models such as AI-ESTATE (Sheppard and Kaufmann, 1999).

In a similar vein, IEEE is also developing standards such as the Automatic Test Markup Language (S.1671.4, 2008) and the Software Interface for Maintenance Information Collection and Analysis (Sheppard and Wilmering, 2006) as a means to standardize the exchange of test information between automatic test equipment.

From a lessons learned perspective on the JSF program, a well integrated information system has been identified as the most important lesson learned (Hess and Fila, 2002). This lesson includes ensuring that ground systems are developed jointly with diagnostic systems and that on-board diagnostic algorithms are developed in a manner to ensure full system capability.

There is a great difference between supply chain management for a large operation consisting of a uniform fleet and managing a very small number of highly unique and complex vehicles (such as NASA's Shuttle Orbiter program). With a small number of vehicles requiring custom part specifications, the lead time to the vendors needs to be maximized, and having an inventory of such spare parts is advisable. In the case of large fleets where multiple sources are available for parts and supplies, a just in time inventory approach can help minimize waste and storage expenses. Turn-around time can be optimized through proper planning and use of analytical and prediction capabilities of fleets.

\subsection{Flight}

DEFINITION: The Flight category includes the pilots and flight crew as well as those responsible for Safety of Flight. 
The bottom line for flight objectives for health management systems is to only provide information that increases certainty for future actions and commands and increases safety of flight.

Table 2 list objectives related to flight. A clear violation of the information certainty objective is false alarms alerting the crew to a problem in a subsystem when the problem does not really exist.

A second objective, also related to reducing uncertainty in the cockpit, is the objective not to have conflicting alarms - also known as dissonance (Pritchett et al., 2002; Song and Kuchar, 2003). This objective can unfortunately be derived from a lessons learned from a tragic flight accident. In July 2002 a mid-air collision occurred between a Russian passenger jet and a DHL cargo jet over Germany which resulted in 71 deaths. Analysis of this accident revealed a dissonance problem between an onboard alerting system called the Traffic Alert and Collision Avoidance System and an air traffic controller whereby the Traffic Collision Avoidance System commanded the pilot to gain altitude to avoid a collision and the control tower commanded a decrease in altitude. The conflicting signals, even if the pilot can prioritize, cause time delays in executing the appropriate action.

Table 2. Flight User Goals and Metrics (d: diagnostics, p: prognostics)

\begin{tabular}{|c|c|c|}
\hline Flight Goals & User Metrics & Map \\
\hline $\begin{array}{l}\text { F.1 Minimize } \\
\text { cockpit false alarm } \\
\text { rate }\end{array}$ & $\begin{array}{l}\text { Time between false } \\
\text { alarms }\end{array}$ & $\mathrm{d}, \mathrm{p}$ \\
\hline $\begin{array}{l}\text { F. } 2 \text { Minimize } \\
\text { cockpit information } \\
\text { overload }\end{array}$ & $\begin{array}{l}\text { \# health } \\
\text { management } \\
\text { messages }\end{array}$ & $\mathrm{d}, \mathrm{p}$ \\
\hline $\begin{array}{l}\text { F.3 Enable cockpit } \\
\text { information filtering } \\
\text { of critical alarms }\end{array}$ & $\begin{array}{l}\text { Capability to filter - } \\
\text { pilot satisfaction }\end{array}$ & $\mathrm{d}, \mathrm{p}$ \\
\hline $\begin{array}{l}\text { F.4 Enable cockpit } \\
\text { information filtering } \\
\text { of non-critical } \\
\text { alarms }\end{array}$ & $\begin{array}{l}\text { Capability to filter - } \\
\text { pilot satisfaction }\end{array}$ & $\mathrm{d}, \mathrm{p}$ \\
\hline $\begin{array}{l}\text { F. } 5 \text { Minimize alarm } \\
\text { conflicts }\end{array}$ & \# conflicting alarms & $\mathrm{d}, \mathrm{p}$ \\
\hline $\begin{array}{l}\text { F.6 Minimize alarm } \\
\text { dissonance }\end{array}$ & $\begin{array}{l}\text { \# alarms that have } \\
\text { disparity between } \\
\text { ATC and alarms }\end{array}$ & $\mathrm{d}, \mathrm{p}$ \\
\hline $\begin{array}{l}\text { F.7 Maximize time } \\
\text { from first alert to } \\
\text { failure. }\end{array}$ & $\begin{array}{l}\text { Time to failure or } \\
\text { when safe landing } \\
\text { becomes difficult. }\end{array}$ & $\mathrm{d}, \mathrm{p}$ \\
\hline F.8 Enhance Safety & \# aborted flights & $\mathrm{d}, \mathrm{p}$ \\
\hline F.9 Enhance Safety & \# smoke events & $\mathrm{d}, \mathrm{p}$ \\
\hline F.10 Enhance Safety & $\begin{array}{l}\text { Passenger comfort } \\
\text { complaint rate }\end{array}$ & $\mathrm{d}, \mathrm{p}$ \\
\hline
\end{tabular}

The flight crew also needs to have as much advanced knowledge of an imminent failure as practical (Vincent and Pritchett, 2001). In particular, pilots need to be alerted early enough that the fault can be resolved and control regained (if lost) or if the handling qualities are too severely degraded, the health management system should be able to augment vehicle control stability in conjunction with a damage adaptive controller to enable a safe emergency landing.

The ability for crew to prioritize, although essential, is one that is easily overloaded when either too much information is presented or when the most critical information is either buried beneath layers of information or is not easily accessible (multiple submenus). This relates to both optimizing the number of health management messages sent to the crew as well as allowing for the crew to appropriately filter the less critical messages.

There is a lack of understanding in the community as to "how good is good enough" and "how good can we get" with respect to fault diagnosis. This is intimately connected with practical issues such as performance metrics and false alarm rates. In the past, on-board diagnostic systems have had a terrible record for costing more then was saved. For example, in Bain and Orwig (2000) it is documented that built-in-tests (BIT) caused wasted (CND) maintenance of the order of 85,639 maintenance man hours and 25,881 hours unnecessary aircraft downtime. This issue has plagued the F/A-18E/F and the V-22 Osprey (Westervelt, 2006).

Of course the top priority of the flight crew is safety. Typically safety can be measured in terms of the number of aborted flights, number of National Transportation Safety Board (NTSB) incident and accident reports, number of smoke events (when the smell or sight of smoke is present), and number of passenger comfort complaints (air quality, water quality, temperature...).

As the safety of air transportation continues to improve, the impact of health management systems on safety becomes increasingly difficult to measure. Nevertheless, the introduction of health management technology should always be required to improve safety. There is always risk from the introduction of technology that needs to be weighed and mitigated so that safety margins are always improving.

\subsection{Maintenance}

DEFINITION: Maintenance health management users are defined as the personnel in the depots and on the field responsible for repairing and servicing the aircraft. 
Table 3. Maintenance User Goals and Metrics (d: diagnostics, p: prognostics)

\begin{tabular}{|c|c|c|}
\hline Maintenance Goals & User Metrics & Map \\
\hline $\begin{array}{l}\text { M.1 Decrease incidents } \\
\text { of cannot duplicate } \\
\text { (CND) logs and retests } \\
\text { OK (RTOK) }\end{array}$ & \# CNDs & $\mathrm{d}$ \\
\hline M.2 Reduce failures & MTBF & $\mathrm{p}$ \\
\hline $\begin{array}{l}\text { M.3 Increase operation } \\
\text { after non-critical faults }\end{array}$ & $\begin{array}{l}\text { Time of } \\
\text { operation after } \\
\text { non-critical fault }\end{array}$ & $\mathrm{p}$ \\
\hline $\begin{array}{l}\text { M.4 Reduce damage } \\
\text { incurred }\end{array}$ & $\begin{array}{l}\text { \# damage } \\
\text { incidents logged } \\
\text { as caused by } \\
\text { maintenance }\end{array}$ & $\mathrm{p}$ \\
\hline $\begin{array}{l}\text { M.5 Reduce maintenance } \\
\text { look-up time }\end{array}$ & $\begin{array}{l}\text { Time to access } \\
\text { maintenance } \\
\text { manuals and } \\
\text { records }\end{array}$ & d \\
\hline $\begin{array}{l}\text { M.6 Identify fault } \\
\text { location }\end{array}$ & $\begin{array}{l}\text { distance to fault } \\
\text { in wiring, LRC } \\
\text { identification }\end{array}$ & d \\
\hline $\begin{array}{l}\text { M.7 Reduce health } \\
\text { management system } \\
\text { maintenance }\end{array}$ & $\begin{array}{l}\text { Hours spent on } \\
\text { diagnosing and } \\
\text { repairing the } \\
\text { health } \\
\text { management } \\
\text { system }\end{array}$ & $\mathrm{d}, \mathrm{p}$ \\
\hline $\begin{array}{l}\text { M.8. Maximize fault } \\
\text { coverage }\end{array}$ & $\begin{array}{l}\text { Percentage of } \\
\text { detectable faults }\end{array}$ & d \\
\hline
\end{tabular}

The bottom line for maintenance is to as quickly and as inexpensively as possible return an aircraft to service while minimizing repeated repairs.

The most costly and most time consuming type of faults are intermittent faults seen during flight that cannot be duplicated (CND) in the maintenance depot. These faults may not be discovered by static depot tests. The dynamic environment of flight may cause faults which only manifest in flight. These types of faults result in subsystems (e.g. Line Replaceable Units - LRUs) being pulled for testing unnecessarily resulting in excessive inventory of parts that retest OK (ROK), excessive time spent on testing and trying to diagnose LRUs that actually are not faulty, and test flights trying to pin down the correct diagnosis. Health management systems hold the allure that a correct diagnosis (fault type and location) can be provided without intervention by the maintenance personnel. This would both reduce the incidents of CNDs and RTOKs as well as reduce the required labor. Table 3 contains a sampling of the maintenance objectives.

One of the greatest sources of faults for Electrical Wiring and Interconnect Systems comes from poor maintenance
Table 4. Fleet Management Goals and Metrics (d: diagnostics, p: prognostics)

\begin{tabular}{|c|c|c|}
\hline $\begin{array}{l}\text { Fleet Management } \\
\text { Goals }\end{array}$ & User Metrics & Map \\
\hline $\begin{array}{l}\text { FM.1 Life extension - in } \\
\text { service beyond expected } \\
\text { service life }\end{array}$ & $\begin{array}{l}\text { Years past } \\
\text { retirement }\end{array}$ & $\mathrm{p}$ \\
\hline $\begin{array}{l}\text { FM.2 Decrease } \\
\text { unscheduled maintenance }\end{array}$ & $\begin{array}{l}\text { Hours of } \\
\text { unscheduled } \\
\text { maintenance }\end{array}$ & $\mathrm{p}$ \\
\hline $\begin{array}{l}\text { FM.3 Easily } \\
\text { reconfigurable }\end{array}$ & $\begin{array}{l}\text { Time to } \\
\text { respond to } \\
\text { mission } \\
\text { change }\end{array}$ & \\
\hline FM.4 Efficiency & $\begin{array}{l}\text { Fuel used vs. } \\
\text { cargo/people } \\
\text { transported }\end{array}$ & $\mathrm{d}, \mathrm{p}$ \\
\hline $\begin{array}{l}\text { FM. } 5 \text { Vehicle targeted } \\
\text { CBM }\end{array}$ & $\begin{array}{l}\text { (HUMS } \\
\text { examples) }\end{array}$ & $\mathrm{d}, \mathrm{p}$ \\
\hline $\begin{array}{l}\text { FM.6 Decrease ops costs } \\
\text { (RMO) }\end{array}$ & $\begin{array}{l}\text { operating } \\
\text { expenses }\end{array}$ & $\mathrm{p}$ \\
\hline FM.7 Increase availability & $\begin{array}{l}\text { mean turn- } \\
\text { around time }\end{array}$ & $\mathrm{d}, \mathrm{p}$ \\
\hline $\begin{array}{l}\text { FM.8 Provide surge } \\
\text { capacity }\end{array}$ & surge capacity & $\mathrm{p}$ \\
\hline $\begin{array}{l}\text { FM.9 Spare part usage } \\
\text { analytics. }\end{array}$ & $\begin{array}{l}\text { Percent } \\
\text { accuracy on } \\
\text { part usage } \\
\text { predictions. }\end{array}$ & $\mathrm{p}$ \\
\hline $\begin{array}{l}\text { FM.10 Aid business and } \\
\text { regulatory decisions }\end{array}$ & & $\mathrm{d}, \mathrm{p}$ \\
\hline $\begin{array}{l}\text { FM.11 Improve design } \\
\text { and qualifications }\end{array}$ & & $\mathrm{d}, \mathrm{p}$ \\
\hline
\end{tabular}

practices (Collins and Edwards, 2005). For example, if a new wire needs to be run, rather than unscrew the wire clamps and undo the wire ties along the harness it is quicker to just push the wire through the clamps and ties if it will fit. This can have the consequence of causing the wire clamps to be too tight resulting in pinching of all of the wires. Over time this can result in abrasion and breakage internal to a wire. Although this problem does not manifest right away, bad practices such as this can reduce the average fleet mean-time between failure (MTBF) values.

A prognostic capability within a health management system provides the capability to predict and trend degradation before eventual failure occurs. The ability for maintenance to reduce subsystem failures by repair and/or replacement prior to failure can be measured in terms of mean time between failures. In the case of the electrical wiring issue, a future electrical diagnostic system could sense the 
abnormal wear within the pinched wires. The prognostic system could then form an estimate as to when the stressed wires would need to be replaced to avoid interruption in service.

An ISHM system also holds the promise to reduce maintenance turn-round time by identifying the location of the fault. For discrete state based systems, the fault coverage can be extensive and enumerated. Fault coverage for analog parameters is much more difficult to ensure than with discrete domains. Typically due to the continuous nature of the range of parametric faults along with the inherent masking effect of process variations there tends to be a range of faults in which are not entirely detectable. This grows worse as variance increases. Two novel test metrics are introduced in Abderrahman et al. (2007) a guaranteed parameter fault coverage obtained by a deterministic method, which is the guaranteed lower bound of PFC, and a partial parameter fault coverage, which is the probabilistic component of PFC. The details of these metrics can be found in Abderrahman et al. (2007).

\subsection{Fleet Management}

DEFINITION: Fleet management health management users are defined as those involved with making fleet wide decisions affecting life extension, operational costs (RMO) and future planning.

The bottom line for fleet management is to maximize adaptability, availability and mission success while minimizing costs and resource usage.

Fleet managers interact with the health management system at a higher level of abstraction than do the other users. The accuracy of the analytics and system assessments is even more critical at this level due to the large consequence of a single misinformed decision. Since fleet management is at such a high level it encompasses the users that we have previously examined such as logistics, flight and maintenance. Table 4 summaries the objectives of fleet management.

Integral to fleet management is the use of decision support systems within an integrated information system. Decision support systems aid business and regulator decisions and improve design and qualifications by emphasizing specific query, reporting and analysis capabilities [44]. This is used both by a fleet owner and operator as well as by original equipment manufacturers (OEMs) (e.g. warranty calculations). This also impacts regulatory affairs by allowing fleet managers to have the information necessary to adhere to strict regulatory inspection intervals and minimize fleet wide disruptions.

\section{DIAGNOSTIC\&PROGNOSTIC SYSTEMS}

The health management system user objectives and metrics will next be related to those metrics associated with development and operation of diagnostic and prognostic systems. Many of these user objectives will map into both diagnostic and prognostic metrics, others will not map into either. An extensive survey on diagnostic metrics was conducted in Kurtoglu et al. (2008). The primary results from this survey are presented in Table 5. Surveys on prognostic metrics, including suggestions as to new metrics for prognostics are presented in (Saxena et al., 2008) and (Laeo et al., 2008). Readers wishing for more insight into performance measures for diagnostics and prognostics are directed to look at Kurtoglu et al., (2008), Szxena et al., (2008), Laeo et al., (2008) and the references contained therein.

\subsection{Diagnostics}

DEFINITION: Diagnosis is the detection and determination of the root cause of a symptom.

The bottom line for diagnostics is to detect and isolate faults in a timely and accurate manner with sufficient resolution so as to identify the specific faulty component.

The objectives and associated metrics for diagnostics taken from [1] are summarized in Table 5. The diagnostic objectives have been categorized into two categories: detect and isolate. Within each of these categories are objectives related to response time, accuracy, sensitivity/resolution and robustness. The previously presented user objectives for logistics, flight, maintenance, fleet management and training can be related to the diagnosis objectives and metrics in Table 5. A summary of this mapping of user goals to diagnostics is summarized in Table 6 . The purpose of this mapping is to present the relationship between published user objectives and the performance measures used to drive diagnostic algorithm research and development.

In order to make this table presentable, we have selected the most important diagnostic measure(s)

Table 5. Diagnostic Metrics (Kurtoglu et al., 2008)

\begin{tabular}{|c|c|c|}
\hline Type & $\begin{array}{l}\text { Diagnostic } \\
\text { Objectives }\end{array}$ & Model Metrics \\
\hline \multirow{7}{*}{$\begin{array}{l}\frac{\vec{e}}{0} \\
\frac{\tilde{0}}{0}\end{array}$} & Time & Response time to detect \\
\hline & Accuracy & Detection false positive rate \\
\hline & Accuracy & Detection false negative rate \\
\hline & Accuracy & Fault detection rate \\
\hline & Accuracy & Fault detection accuracy \\
\hline & Sensitivity & Detection sensitivity factor \\
\hline & Stability & Detection stability factor \\
\hline \multirow{6}{*}{$\frac{\mathscr{\Xi}}{0}$} & Time & Time to isolate \\
\hline & Time & Time to estimate \\
\hline & Accuracy & Isolation classification rate \\
\hline & Accuracy & $\begin{array}{l}\text { Isolation misclassification } \\
\text { rate }\end{array}$ \\
\hline & Resolution & Size of isolation set \\
\hline & Stability & Isolation stability factor \\
\hline
\end{tabular}


for each objective. This ignores many of the points that have been made within this article and should only be considered within that context. For example with MTTR, we have listed accuracy and specificity - this is not to say that timeliness is not important - timeliness is essential as has been pointed out within our discussion.

Note that there are several categories that have been listed as not defined. For example, the ease of using an IS is not clearly defined within the diagnostics development community. One of the user objectives: minimizing alarm dissonance - requires a more systems level approach than can be provided by listing a single diagnostic.

\section{1) Diagnostics for logistics}

All of the measures in Table 5 directly or indirectly impact some of the previously described user metrics. The logistics user goals and metrics (Table 1) relevant to diagnostics are related to the appropriate diagnostic metrics.

Reduce repair turn-around time (L.1) - The user goal of reducing repair turn-around time as measured by the mean time to repair can be facilitated via maximizing the accuracy of fault detection and isolation. An automated diagnostic system that can pin-point the fault type and faulty sub-system component will save technicians time in locating the root cause of the fault symptom. The reduction in repair turn-around time corresponds to the ratio between the time spent diagnosing with respect to the total time of diagnosing and repair. Conversely, a bad diagnosis system will mislead repair personnel and potentially adversely impact the repair turn-around time. Occasionally such misdirections will occur, it is important to evaluate the mean of the reduction in repair turn-around. If the deviation is too high about this mean the repair personnel may stop using the system out of frustration.

Reduce ground support equipment and personnel (L.2) The goal of reducing ground support/footprint as measured by the number of ground support personnel and also by the amount of equipment required to diagnose a fault is related to all the entries of Table 5. If the diagnosis system is quick enough to transmit logistics requests prior to landing, and if the diagnosis is accurate and has high enough specificity (resolution), then right test equipment at the right time may be made available via on-board diagnostics telecasting the appropriate information to maintenance and logistics.

Reduce labor (L.4) - Reducing labor as measured in aggregate labor hours is enabled by ensuring accurate detection and isolation diagnosis as well as a timely solution. If the detection and isolation algorithms take longer to find a solution than the nominal labor required to discover root cause, then the system is a failure. Additionally, if the diagnosis or isolation is wrong too many times, technicians will spend more time to enact repairs and will eventually terminate usage of the diagnostic system.
An independent technical assessment of software for the F-22 determined that the acquisition activity failed to properly interpret and implement fault detection and fault isolation requirements (Marz, 2005). In particular, the following software capability gaps in the integrated diagnostics were highlighted:

\section{Test coverage}

\section{Correlating faults to failures}

a. ability to isolate failures

b. determining the consequence of a failure

\section{Fraction of false alarms / false positives}

4. Software health management - diagnostic environments that monitor software for faults are immature.

Test coverage refers to how many of the physical system failure modes are included within the scope of the diagnosis algorithms. The size of the isolation set (Table 5) refers to how many modes within the model scope are reported in a candidate set (size of the ambiguity group).

Ease of using entire information system (L.8) - The ease of use of the information systems associated with all aspects of the life-cycle is very difficult to measure and has many different meanings. For our purposes, we will relate this to the diagnostic objective of minimizing time to respond. It is very difficult and subjective to measure the performance of an information system from user perspectives. For example, the information needs, access rights and even processing operations vary greatly from logistics, to maintenance and fleet management. Fleet managers may need annualized aggregated statistics whereas maintenance personnel need access to an individual vehicle's repair history and to OEM part replacement procedures.

Minimize inventory (just in time) (L.12) - One of the ways to reduce the need for a large inventory of spare parts is to have a method by which repairs are initiated such that only those parts which need replacement are swapped out. Often times during a diagnostic procedure, a technician will need to swap out parts to try to localize the root cause of the fault. With a diagnostic system capable of accurate fault isolation this behavior of part swapping can be reduced thus impacting the inventory metric. Prognostics can have an even greater impact on minimizing required inventory by predicting wear trends. 
Table 6. Diagnostic Mapping Summary

\begin{tabular}{|l|l|}
\hline $\begin{array}{l}\text { User Community } \\
\text { Goals/Metrics }\end{array}$ & Diagnostic Saliency \\
\hline $\begin{array}{l}\text { Logistics } \\
\text { Min. MTTR }\end{array}$ & $\begin{array}{l}\text { Max. accuracy \& } \\
\text { specificity }\end{array}$ \\
\hline Min. ground support & Max. specificity \\
\hline Min. labor hours & $\begin{array}{l}\text { Max. accuracy \& } \\
\text { specificity }\end{array}$ \\
\hline Ease of use of IS & Not defined \\
\hline Minimize inventory & $\begin{array}{l}\text { Max. accuracy \& } \\
\text { isolation }\end{array}$ \\
\hline $\begin{array}{l}\text { Flight } \\
\text { Min. false alarms }\end{array}$ & Max. accuracy \\
\hline Min. info overload & $\begin{array}{l}\text { Max. accuracy \& } \\
\text { specificity }\end{array}$ \\
\hline Enable info filtering & Max. specificity \\
\hline Min. alarm conflicts & Max. accuracy \\
\hline Min. alarm dissonance & System level issue \\
\hline $\begin{array}{l}\text { Max. alert time from } \\
\text { failure }\end{array}$ & Timeliness \\
\hline Max. safety & All \\
\hline $\begin{array}{l}\text { Maintenance } \\
\text { Min. CND \& RTOK }\end{array}$ & Accuracy \& isolation \\
\hline Reduce look-up time & Not defined \\
\hline Accurate fault location & $\begin{array}{l}\text { Max. isolation and } \\
\text { distance to fault }\end{array}$ \\
\hline Min. HMS maintenance & Not defined \\
\hline Max. fault coverage & Max. coverage \\
\hline $\begin{array}{l}\text { Fleet } \\
\text { Max. efficiency }\end{array}$ & $\begin{array}{l}\text { Accuracy \& } \\
\text { specificity }\end{array}$ \\
\hline Vehicle CBM & Accuracy \\
\hline Aid business decisions & Not defined \\
\hline Improve design & Not defined \\
\hline
\end{tabular}

\section{2) Diagnostics for flight}

Automated diagnostics for the flight crew has more critical factors with respect to timeliness of reporting than logistics requires. The crew needs enough time to be able to either resolve the fault condition or to respond and plan for an emergency landing. Another metric within Table 5 that pertains to diagnostics for the flight crew is the measure of the number of false alarms.

Minimize cockpit false alarm rate (F.1) - The minimization of cockpit false alarms as measured by the time between false alarms is obviously mapped directly to the detection false positive rates. The metric of time between false alarms is not necessarily the optimal measure, not all false alarms will be treated equally by the crew. There is a measure of criticality that needs to be added to this metric.
Minimize cockpit information overload (F.2) Information overload can cause crew to miss critical messages as well as to create patterns of behavior whereby ignoring messages is rewarded due to misinformation. In part this can be alleviated by improving the accuracy and specificity of the provided diagnostic information. Additionally, since different user preferences will prevail, there needs to be information filtering capabilities.

Enable cockpit information filtering of critical alarms as measured by pilot's satisfaction $(F .3, F .4)$ - The capability to filter critical cockpit alarms can be measured by surveying pilot satisfaction. Whenever a metric involves measuring human satisfaction, the complexities can be enormous. The ability to filter messages can be considered independent from the diagnostic system as long as inaccuracies are mitigated. It is often the case that human factor issues are not adequately considered when diagnostics are developed at the sub-system level. These human centric issues become more apparent at a systems integration level.

Minimize alarm conflicts as measured by number of conflicting alarms and minimize alarm dissonance as measured by number of alarms that have disparity (F.5, F.6) - The number of conflicting alarms and the number of alarms that have disparity can be indicators of overall system integration. Many times diagnostics are developed independently for sub-systems by different vendors and then the central diagnostic system is responsible for reconciliation of all of those systems. The conflicts definitely arise from the error statistics of the individual sub-systems but there is a higher level of functionality that is not represented individually. The performance of minimizing conflicts can be measured by the accuracy and resolution of the integrated system. Alarm conflicts may involve dissonant information creating conflict between the control tower and the advisory cockpit warnings.

Even in the absence of control tower communications, cognitive dissonance resulting from alarms may cause a loss of situational awareness among the crew members and lead to incorrect actions being taken. This level of system integration is typically beyond scope of the majority of diagnostic and prognostic engineers.

Maximize time from first alert to failure as measured by time to failure or when landing becomes difficult (F.7) - Maximizing the in-flight timeliness of a diagnostic is critical to both giving the flight crew adequate time to plan and respond as well as giving the ground logistics time to implement a maintenance plan. Typically there is a trade-off between early detection and false alarms. It is frequently the case that early detection can only be made when more false alarms are allowed to be incurred. This trade-space needs to be weighed carefully with respect to the criticality of the failure 
and the amount of time really required to prepare for a safe landing.

Safety as measured by number of incidents (e.g. smoke events) or number of aborted flights (F.8-F.10). Obviously underlying all improvements in all of the other categories is the need to always be maintaining or improving safety margins. All aspects of diagnostics relate to safety.

\section{3) Diagnostics for maintenance}

Decrease incidents of cannot duplicate (CND) logs and retests $O K$ (RTOK) (M.1) - The maintenance health management users metric for the number of CND logs will be positively impacted by accurate fault detection and isolation.

Reduce maintenance look-up time (M.5) - Legacy systems can make even the simplest task take considerable time. For example, repairing a broken sensor wire requires that the maintenance personnel be able to lookup that particular sub-system in the OEM manuals to determine the wire type, correct size and routing. This information can be buried in obscure encodings and difficult to use manuals that are not readily accessible electronically in the maintenance bay. As diagnostic systems become more sophisticated, it is important that they make the necessary information immediately available to those personnel that will facilitate the repair.

Fault location (M.6) - Fault location is a bit trickier to map directly to Table 5, which lists fault isolation. Fault isolation in some sense implies more a discrete state-space approach. There are certainly subsystems such as electrical wiring, wherein both fault isolation and fault localization are different. For example, fault isolation determines which wire or wire bundle (or connector) is responsible for the given fault symptoms; whereas fault localization specifies the precise location (distance to fault) of the damage on the wire responsible for the fault. This will become an increasingly important distinction as arc fault circuit breakers come into operation. An arc fault circuit breaker is designed to interrupt the circuit once an arcing condition has been detected. Unfortunately, by the time arcing has been detected, there will be damage present on at least one wire. This damage will typically be just a small spot (a consequence of an effective breaker) and may be very difficult to find via visual inspection without location information.

Health management system maintenance (M.7) - Another aspect that is unique to diagnosis is the maintenance required to maintain the health of the diagnostic health management system. Although this does not appear in Table 5, the maintenance objectives for the diagnostic health management system need to be one of the factors within the model metrics. It is important that such issues as sensor fatigue/failure be diagnosed appropriately rather than misclassified as a fault with the system that the sensor(s) is measuring. Although time and money savings will be incurred through a healthy health management system, if the maintenance of the HMS consumes all of these savings then a net result has been to increase risk to safe operation of the vehicle. Another application where fault localization is of great importance is structural health management.

Fault coverage (M.8) - Fault coverage for discrete fault states indicates the percentage of faults that the diagnosis system is able to detect and diagnose. It is important that the fault coverage includes the health management system itself so that technicians are better able to direct their attention to the appropriate sub-system. For continuous fault states, the coverage indicates the ability to detect faults within acceptable limits. Fault coverage is impacted by the resolution of the diagnostic system. A system that has broad coverage but is not able to localize will not have much of an impact on turnaround time. This is also related to the isolation set which determines the resolution of the diagnoses.

\section{4) Diagnostics for fleet management}

Diagnostics for fleet management has the potential to reduce the number of maintenance hours and thereby positively impact the user metrics of mean turn-around time and hours of unscheduled maintenance, although the number of maintenance activities will not likely decrease. Ultimately, the other fleet user objectives and additionally the unscheduled maintenance metric will be impacted by an effective prognostic system.

Efficiency (FM.4) - All systems on a vehicle may be running within nominal operating ranges but peak efficiency may not be achieved when some systems are near the edge of nominal behavior. The ability to trend these in prognostics will have the greatest impact on improving and maintaining optimal performance efficiencies.

Vehicle targeted CBM (FM.5) - Condition based maintenance, with sufficient information technology infrastructure, can be targeted to individual vehicles making it possible to optimally maintain a vehicle based upon its history as well as operating context. An accurate and specific diagnosis system integrated within a larger information system can enable vehicle targeted CBM.

Increase availability (FM.7) - Diagnostics can aid in increasing average fleet availability by minimizing the mean time to repair (by providing accurate diagnoses). Prognostics will have an even greater impact by minimizing the down time attributable to unscheduled maintenance fleetwide.

Aid business and regulatory decisions (FM.10) Well thought out system integration is essential for diagnostics to be able to impact business decisions. For example as a fleet ages, vehicles start to exceed the original expected life, failures may start to be diagnosed in a few vehicles that are both the source of unscheduled maintenance as well as indicative of 
a bad trend. These fleet wide diagnosis trends can be analyzed to determine when is the optimal time to schedule replacement of parts in the non-failed part of the fleet prior to failure but without prognostics or trending degradation.

Improve design and qualifications (FM.11) - As parts are diagnosed as failing, there may be fleet wide occurrences of component failures that were not expected by the engineers. A diagnostic system that is well integrated into a fleet wide information system can alert engineering that an analysis needs to be performed to determine if these components will continue to fail at an unexpected rate thus warranting a design improvement.

\subsection{Prognostics}

DEFINITION: Prognostics is defined as the ability to detect, isolate and diagnose mechanical and electrical faults in components as well as predict and trend the accurate remaining useful life (RUL) of those components (Banks and Merenich, 2007).

The bottom line for prognostics is to as accurately and as far in advance as possible predict the remaining useful life of components and consumables to aid in logistics management, maintenance planning, crew alerting (impending failure) and fleet-wide planning. From a maintenance perspective:

"The goal of the prognostics portion of PHM is to detect the early onset of failure conditions, monitor them until just prior to failure, and inform maintenance of impending failures with enough time to plan for them. This will, in effect, eliminate the need for many of the inspections, as well as provide enough of a lead time to schedule the maintenance at a convenient time and to order spare parts in advance." (Hess and Fila, 2007)

The prognostics discussion will for the most part not overlap with the previous discussion of diagnostics even though many of the points are strongly inter-related. Specifically, if a system cannot reliably detect a fault useful for diagnosis it will prove very difficult to accurately assess the remaining useful life of such a component. For diagnosis (Table 5) we broke the field into two types: detect and isolate. For each of these types we had measures for time, accuracy, sensitivity/resolution and stability. The model metrics for prognostics are taken from two overviews of performance metrics: (Saxena et al., 2008) and (Leao et al., 2008) as summarized in Table 7.

The detect category for prognosis has a different meaning from detect in diagnosis. As an example, consider the meaning of false positive for each. A false positive in diagnosis detection means that the diagnosis system detected and indicated a fault where none existed. However, a false positive in prognosis means that a prediction of failure is unacceptably early resulting in loss of usable service life. Thus, prognosis detection is with respect to a time horizon which depends on user requirements. Typically the notion of detection in diagnosis is not relative to a time horizon. For prognosis
Table 7. Prognostic Model Metrics (Saxena et al., 2008 and Leao et al., 2008)

\begin{tabular}{|c|c|c|}
\hline Type & $\begin{array}{l}\text { Prognostic } \\
\text { Objectives }\end{array}$ & Model Metrics \\
\hline \multirow{2}{*}{ 遶 } & $\begin{array}{l}\text { Accuracy of } \\
\text { characterization }\end{array}$ & $\begin{array}{l}\text { Early prediction, } \\
\text { late prediction } \\
\text { (with respect to } \\
\text { time window) }\end{array}$ \\
\hline & $\begin{array}{l}\text { Missed estimation } \\
\text { rate }\end{array}$ & $\begin{array}{l}\text { \# missed } \\
\text { detections/total \# } \\
\text { prognoses }\end{array}$ \\
\hline \multirow{5}{*}{ : } & $\begin{array}{l}\text { Accuracy of predict } \\
\text { remaining useful life }\end{array}$ & $\begin{array}{l}\text { Accuracy at } \\
\text { specific times } \\
\text { (error, average } \\
\text { error) }\end{array}$ \\
\hline & Minimize sensitivity & $\begin{array}{l}\text { Sampling rate } \\
\text { robustness }\end{array}$ \\
\hline & Precision & $\begin{array}{l}\text { Ratio of precision } \\
\text { to horizon length, } \\
\text { standard deviation }\end{array}$ \\
\hline & Hit rate & $\begin{array}{l}\text { \# correct } \\
\text { prognoses/total \# } \\
\text { of prognoses }\end{array}$ \\
\hline & Timeliness & $\begin{array}{l}\text { Prognostic horizon, } \\
\text { accuracy at specific } \\
\text { times, convergence } \\
\text { rate }\end{array}$ \\
\hline \multirow{2}{*}{$\underset{\substack{\frac{\pi}{0} \\
0}}{0}$} & $\begin{array}{l}\text { Phase difference } \\
\text { between samples } \\
\text { and prediction. }\end{array}$ & $\begin{array}{l}\text { Anomaly } \\
\text { correlation } \\
\text { coefficient }\end{array}$ \\
\hline & $\begin{array}{l}\text { Precise correct } \\
\text { estimation rate }\end{array}$ & $\begin{array}{l}\text { \# correct prognoses } \\
\text { without adequate } \\
\text { resolution }\end{array}$ \\
\hline \multirow{4}{*}{ : } & $\begin{array}{l}\text { Minimize number of } \\
\text { required sensors }\end{array}$ & $\begin{array}{l}\text { Reduced feature set } \\
\text { robustness }\end{array}$ \\
\hline & $\begin{array}{l}\text { Minimize amount of } \\
\text { data needed }\end{array}$ & Data frame size \\
\hline & Prognosis effectivity & $\begin{array}{l}\text { \# avoided unsched. } \\
\text { maint. events/total } \\
\text { \# of possible } \\
\text { unsched. events for } \\
\text { component }\end{array}$ \\
\hline & Average bias & $\begin{array}{l}\text { average wasted life } \\
\text { of component }\end{array}$ \\
\hline
\end{tabular}

we have added two more types to detect and isolate: predict and effectivity. Similar to the diagnosis table, within these categories are objectives related to accuracy, time, sensitivity and effectiveness. 
The last type: effectivity relates very much to engineering design trade-space. Designing a system to make diagnosis and prognosis easier is an extensive subject that is beyond the scope of this paper. However, the effectivity section is very much related to the cost benefits analysis discussion.

The metrics employed in prognostic algorithm research and development are shown in Table 7 as taken from (Saxena et al., 2008) and (Leao et al., 2008) The mapping between the user goals and the prognostic metrics are listed in Table 8. As was true with the mapping from user objectives to diagnosis, the purpose of this mapping is to present the relationship between published user objectives and the performance measures used to drive prognostic algorithm research and development. We will not repeat elements covered in the diagnosis discussion, we chose to highlight items specific to prognosis. The considerations and caveats implored for Table 6 apply to Table 8 as well. Higher level functions such as business analytics and decision support systems which are functions of prognostics have not been defined within the prognostics measures.

\section{1) Prognostics for logistics}

The logistics goals unique to prognosis from diagnosis are discussed hence.

Increase availability/decrease unscheduled maintenance (L.3) - Decreasing unscheduled maintenance (and therefore increasing availability) is directly enabled through accurate degradation trend prediction combined with adequate time horizons. The time horizon needs to be long enough to allow for proper scheduling of maintenance and logistics as well as to plan for the usage of replacement aircraft. Obviously, accuracy in prediction of remaining useful life is critical to not waste part life through premature replacement. Incorrect estimates are even worse in that they will result in replacement of good parts and unnecessary downtime or even worse - failed parts that would have otherwise been replaced before failure. The positive impact on availability of prognostics is great but the risk posed by inaccurate prognostics is equally great.

Reduce periodic inspections (L.5) - The U.S. Air Force is employing condition based maintenance techniques combined with usage predictions to change the frequency of inspections and replacements based upon usage. The impact on the commercial sector with such technology depends largely on regulatory affairs (FAA). The current regulations need to take into account the ability to monitor and predict degradation trends as a means to reduce periodic inspections. Accuracy of the predictions of remaining useful is essential to avoid replacing parts that still have good life left and to avoid unscheduled maintenance due to unpredicted failures.

Predict remaining useful life in components, maximize component life usage and tracking (L.6) - Maximizing component life usage means having the ability to accurately know when an isolated component will fail with enough lead time so as to be able to schedule replacement.
Obviously this relies upon accuracy of predictions as well as having an adequate time horizon and being able to isolate trends to specific components.

CBM - Schedule regular maintenance only as necessary - Predict remaining useful life in expendables (e.g., oil) (L.7) - One of the first applications of prognostics has been in assessing the state of consumables such as oil. Oil can be monitored for its quality, for contaminants, and for quantity. The trend of the degradation of the oil can then be predicted and used to optimally schedule maintenance for replacement/renewal.

Provide surge capacity (L.9) - The ability to delay or adjust maintenance windows provides the capability of supporting surges in operations. Accurate health predictions aid in understanding the limits to possible delays and adjustments.

Reduce costs of reconfigurations and turn-arounds (L.10) - Unusual or unanticipated maintenance problems can result in costly reconfigurations of the supply chain or interruption of typical logistics processes. The ability to quickly and accurately identify the causes of faults and predict failures results in less disruption to establish procedures and protocols, thereby saving time and money. Additionally, planned reconfigurations can be scheduled to incorporate preventive maintenance that might not otherwise have occurred if not for accurate predictions of remaining useful life of components.

Maximize vendor lead time (L.11) - For parts that infrequently need to be replaced, but which require significant lead time for production and/or are expensive to maintain in inventory the ability to predict far in advance the trend in degradation is important. This relies upon have accuracy in prediction and isolation with enough time horizon to facilitate logistics part ordering.

Minimize inventory (L.12) - Minimizing the required inventory by transitioning to a just-in-time inventory system requires both an adequate time horizon in the remaining useful life estimate as well as specificity so that there is enough time to order the correct parts.

\section{2) Prognostics for flight}

Although all of the elements of Table 2 have been covered in the discussion of diagnostics, we would like to discuss again one of the elements that can be positively impacted by prognostics.

Maximize time from first alert to failure (F.7) Whereas diagnosis is responsible for detecting fault conditions - hopefully prior to full failure prognosis is responsible for predicting the trend in degradation resulting in an estimate of the remaining useful life along with appropriate estimates of 
Table 8. Prognostic Mapping Summary

\begin{tabular}{|c|l|}
\hline $\begin{array}{l}\text { User Community } \\
\text { Goals/Metrics }\end{array}$ & Prognostic Saliency \\
\hline $\begin{array}{l}\text { Logistics } \\
\text { Max. mean time in } \\
\text { service }\end{array}$ & $\begin{array}{l}\text { Max pred. accuracy \& } \\
\text { time }\end{array}$ \\
\hline Max. surge capacity & Accuracy of predictions \\
\hline Min. freq. of inspections & Accuracy of predictions \\
\hline Predict life remaining & $\begin{array}{l}\text { Accuracy, time, } \\
\text { isolation }\end{array}$ \\
\hline CBM & Accuracy \\
\hline Max. vendor lead time & Accuracy and isolation \\
\hline Minimize inventory & Accuracy and timeliness \\
\hline $\begin{array}{l}\text { Flight } \\
\text { Max. alert time from } \\
\text { failure }\end{array}$ & Time horizon, isolation \\
\hline $\begin{array}{l}\text { Maintenance } \\
\text { Reduce failures - MTBF }\end{array}$ & Accurate prediction \\
\hline Increase op after fault & $\begin{array}{l}\text { Accurate trends and } \\
\text { isolation }\end{array}$ \\
\hline Reduce damage incurred & Accurate trending \\
\hline Min. HMS maintenance & Effectivity \\
\hline $\begin{array}{c}\text { Fleet } \\
\text { Max. life extension }\end{array}$ & Accuracy of predictions \\
\hline Min. unscheduled maint & Accuracy \& isolation \\
\hline Min. RMO costs & Accuracy of predictions \\
\hline Spares analytics & Not defined \\
\hline Aid business decisions & Not defined \\
\hline & \\
\hline
\end{tabular}

uncertainty (confidence bounds). This distinction for inflight is critical marking the difference between, for example, stating that hydraulic pump is faulty versus warning that the performance of the hydraulic pump is trending downwards but will be operational for several more hours. Thus an accurate estimate of remaining useful life provides the flight crew with more options as well as providing logistics and maintenance more options for scheduling repairs.

\section{3) Prognostics for maintenance}

Reduce failures (M.2) - Currently when a component or sub-system fails that is not expected to fail the result is unscheduled maintenance and downtime for the vehicle. The hope of prognostics is that some of these unscheduled maintenance activities may be mitigated by trend prediction of degradation. With an accurate modeling of the trending, estimates of remaining useful life can be used to facilitate repair/replacement of components prior to failure thus resulting in reduced unscheduled maintenance. The trade-off is that if the prognostic system is overly conservative wasted component life will occur.

Increase operation after non-critical faults (M.3) - Some faults that have either been detected or are trending can be safely deferred for maintenance to avoid operation interruption. It is critical that a detected fault is highly accurate and isolated and that the prediction of the trend also be highly accurate. The liability for the operator ignoring a fault due to misinformation from the prognostic system is high and every validation and redundant verification needs to be enacted.

Reduce damage incurred (M.4) - Electrical arc fault interruption circuit breakers are designed to augment traditional thermal based circuit breakers by monitoring for the electrical signature associated with arcing events and then cutting off the current flow to the arcing wire. The extension to this is to incorporate a chafing detection system to these breakers to be able to assess the state of wire insulation degradation with the aim of providing both a remaining useful life estimate as well as a distance to fault assessment. The ability to detect chafes prior to an arcing event allow for inspections and maintenance to be scheduled prior to damage occurring from arcing.

Of course underlying all of the remaining useful life (RUL) estimates produced by a prognostic system are stochastic processes. This revelation requires that a probabilistic sensitivity analysis be included as part of the validation and verification process of new prognostic systems (Kacprzynski et al., 2004). This also means that "saying a widget will fail in 100 hours is not sufficient. Saying that a widget will fail in 95 to 105 hours with 94 percent confidence is much more useful." (Line and Clements, 2006).

\section{4) Prognostics for fleet management}

Life extension - in service beyond expected service life (FM.1) - One of the consequences of operating a fleet beyond expected service life is an increasing in maintenance, both scheduled (more frequent) and unscheduled. The promise of prognostics is that the trend analyses can help mitigate unscheduled maintenance. More frequent maintenance may also be mitigated through careful monitoring if the appropriate regulatory authorities concur.

Decrease unscheduled maintenance (FM.2) - This is one of the greatest promises of prognostics, the ability to trend and predict the remaining useful life of a component prior to failure. The accuracy and specificity of such a prediction can enable maintenance to be performed as convenient but prior to failure. This should reduce the number of unscheduled maintenance occurrences.

Decrease ops costs (RMO) (FM.6) - A large factor in aging RMO costs stems from unscheduled maintenance. If this unscheduled maintenance can be mitigated with prognostics, then the RMO costs can be maintained at a more uniform level as the fleet age increases. 
Provide surge capacity (FM.8) - The capability of being able to predict when a component will fail translates to the ability to schedule maintenance at a greater convenience. Greater flexibility in scheduling maintenance enables being able to provide planned surges in capacity.

Spare part usage analytics and business decisions (FM.9) - Usage and repair analytics are a higher level analysis function that require a highly integrated information system combined with the diagnostic and prognostic systems.

\section{DISCUSSION}

As a result of this survey we have found that although the metrics associated with diagnostic and prognostic algorithm and system performance will positively impact the user community, that there are gaps within the diagnostic and prognostic metrics. These gaps tend to fall within one of the following categories:

\section{- Process}

- System analysis

- Data management

- Verification and validation

- Human factors

Process - Large scale adoption of a fully integrated health management system requires buy-in from many different types of users as well as proper systems analysis methods to make the return on investment business case. Objectives and requirements should be generated from inclusion and ownership of a broad spectrum of users. Cost benefit analyses and education of users and management about benefits of health management help with the adoption.

It is possible for the best ideas in health management system development and operation to be foiled by archaic business policies. Cost savings ideas such as "Replace only on failure" as pointed out in ()Yukish et al., 2001) will result in a health management system showing no benefits. In other words, one of the biggest obstacles to health management system adoption is the undocumented human element. Buy-in must be obtained at all user levels for the successful adoption.

System analysis - Another large obstacle is the development of sophisticated technologies without a view to the greater system. This problem is often encountered with engineering development efforts devoted to subsystem diagnostics and prognostics. This system level perspective is often not considered by researchers in diagnostics and prognostics.

Each subsystem within diagnostics or prognostics can be engineered to successfully meet appropriate metrics but fail when verification and validation of the broader system are considered. This means that a broader perspective on verification and validation of total system health management is needed where the whole system requirement is greater than the sum of the user requirements.

Data management - In addition to the system level perspective, there are integration issues, especially within the context of a broader information system, that will not be addressed directly by sub-system requirements or user requirements and yet will vastly impact perceptions of utility. Issues such as business analytics and decision systems are typically not directly considered with diagnostics and prognostic and yet are direct consumers of the information that is sourced from such systems.

Verification and validation - As OEMs start to outsource more subsystem developments, the total system validation and verification becomes a greater challenge. In particular, the $\mathrm{V} \& \mathrm{~V}$ of complex interacting software systems would benefit from a model based verification approach as adopted by hardware developers. Ofstun (2002) also discusses that proper verification and validation of IVHM functionality cannot simply be verified in a laboratory, that incremental demonstrations need to be conducted and that after delivery anomalies will occur and the IVHM system needs to be easy to update.

Human factors - The human element is hard to quantify and easier to ignore than other performance metrics. In particular, issues such as alarm dissonance and conflicts derive from system wide activities not directly measured by any particular subsystem metric are hard to manage and mitigate.

\section{SUMMARY}

We have briefly surveyed the recent literature pertaining to user goals for aeronautic health management systems. We have compared these goals with the results from surveys of the objectives and metrics of diagnostic and prognostic method developments. Although many of the mappings have been concerned with diagnosis accuracy and isolation as well as the horizon and accuracy of prognosis prediction, some of the most interesting information is in the gap between user goals and the success metrics associated with diagnostics and prognostics.

NASA's Aviation Safety Program is investing in IVHM. NASA's IVHM project seeks to develop (http://www.aeronautics.nasa.gov/programs_avsafe. htm) validated tools, technologies, and techniques for automated detection, diagnosis and prognosis that enable mitigation of adverse events during flight. The project includes a systems analysis aspect that assesses i) future directions and technology trends in research related to detection, diagnosis, prognosis, and mitigation as they pertain to the stated goals of the IVHM project, and ii) 
requirements for future aircraft and the issues arising from current and near-term aviation technology. We note that while the primary focus of the IVHM project is on-board, the health management objectives discussed in this paper impact the entire aircraft life-cycle.

Other studies have developed lists of lessons learned with respect to aeronautic health management systems (Ofstun, 2002). In particular, (Novis and Powrie, 2006) points out that holistic approach which views the system as a whole rather than as a collection of parts is essential. This is also true regarding generating user requirements and garnering broad organizational support.

It is our hope that this survey of user objectives as well as the mapping from user objectives to diagnostic and prognostic metrics can further the widespread adoption of health management technologies within aeronautics.

\section{ACKNOWLEDGMENT}

We extend our gratitude to Joseph Totah (NASA), Richard Ross (NASA), and many others for valuable discussions in establishing the IVHM user requirements.

This research was supported in part by the National Aeronautics and Space Administration (NASA) Aeronautics Research Mission Directorate (ARMD) Aviation Safety Program (AvSP) Integrated Vehicle Management (IVHM) Project. Additionally, this material is based upon the work supported by NASA under award NNA08CG83C.

\section{REFERENCES}

10303-1, "Industrial automation systems and integration Product data representation and exchange Part 1: Overview and fundamental principles." 1994.

I. 1636.1, "IEEE Trial-Use Standard for Software Interface for Maintenance Information Collection and Analysis (SIMICA): Exchanging Test Results and Session Information via the eXtensible Markup Language (XML)," February, 2008.

I. S. 1671.4, "IEEE Trial-Use Standard for Automatic Test Markup Language (ATML) for Exchanging Automatic Test Information via XML: Exchanging Test Configuration Information," April, 2008.

"727 to 787: Evolution of Aircraft Maintenance Systems," Avionics Magazine Special Report:http://www.aviationtoday.com/Assets/Honeyw ellsmall.pdf, 2007.

"DoD Architectural Framework: Vol. 1: Definitions and Guidelines, Vol. 2:Product Descriptions, Vol.3: Architecture Data Description," April, 2007.

Abderrahman A., M. Sawan, Y. Savaria, and A. Khouas, "New Analog Test Metrics Based on Probabilistic and Deterministic Combination Approaches," in 14th IEEE International Conference on Electronics, Circuits and Systems, 2007, pp. 82-85.
Albert A.P., E. Antoniou, S. D. Leggiero, K. A. Tooman, and R. L. Veglio, "A Systems Engineering Approach to Integrated Structural Health Monitoring for Aging Aircraft," Wright-Patterson Air Force Base, Ohio, 2006.

Alford R., "Data Management as the Key to Prognostic Capability," in SAE doD Maintenance Symposium $\backslash \&$ Exhibition, 2007.

Ashby M.J. and R. J. Byer, "An Approach for Conducting a Cost Benefit Analysis of Aircraft Engine Prognostics and Health management Functions," in IEEE Aerospace Conference Proceedings. vol. 6, 2002, pp. 2847-2856.

Bain K. and D. G. Orwig, "F/A-18E/F Built-in-test (BIT) Maturation Process," National Defense Industrial Associated 3rd Annual systems Engineering \& Supportability Conference, October, 2000.

Banks J. and J. Merenich, "Cost Benefit Analysis for Asset Health Management Technology," in IEEE Annual Reliability and Maintainability Symposium, 2007, pp. 95-100.

Banks J., K. Reichard, E. Crow, and E. Nickell, "How Engineers Can Conduct Cost-Benefit Analysis for PHM Systems," in IEEE Aerospace Conference, 2005, pp. 3958-3967.

Boller C., "Ways and Options for Aircraft Structural Health Management," in Smart Materials and Structures. vol. 10, 2001, pp. 432-440.

Byer B., A. Hess, and L. Fila, "Writing a Convincing Cost Benefit Analysis to Substantiate Autonomic Logistics," in IEEE Aerospace Conference. vol. 6, 2001, pp. 30953103.

Collins J.H. and G. Edwards, "The Naval Air Systems Command's Initiatives for Aircraft Wiring Diagnostic Support Equipment for Multiple Maintenance Levels," Naval Air Systems Command, 2005.

Crow E., "Condition Based Maintenance, the Maintenance Execution Process and the Open Systems Standards, An Overview of Activities at Penn State," in Defense Maintenance Conference Reno, Nevada, 2006.

Hecht H., "Prognostics for Electronic Equipment: An Economic Perspective," in IEEE Reliability and Maintainability Symposium, 2006, pp. 165168.

Hess A. and L. Fila, "Prognostics, from the Need to Reality - from the Fleet Users and PHM System Designer/Developers Perspectives," in IEEE Aerospace Conference. vol. 6, 2002, pp. 27912797.

Hess A., G. Calvello, and P. Frith, "Challenges, Issues, and Lessons Learned Chasing the Big P: 
Real Predictive Prognostics Part 1," in IEEE Aerospace Conference, 2005, pp. 3610-3619.

Hess A., G. Calvello, and T. Dabney, "PHM a Key Enabler for the JSF Autonomic Logistics Support Concept," in IEEE Aerospace Conference, 2004, pp. 3543-3550.

Hoyle C., A. F. Mehr, I. Y. Tumer, and W. Chen, "CostBenefit Quantification of ISHM in Aerospace Systems," ASME 2007 International Design Engineering Technical Conferences \& Computers and Information in Engineering Conference, September 47, 20072007.

Kacprzynski G.J., A. Liberson, A. Palladino, M. J. Roemer, A. J. Hess, and M. Begin, "Metrics and Development Tools for Prognostic Algorithms," in IEEE Aerospace Conference, 2004, pp. 3809-3815.

Kurtoglu T., O. J. Mengshoel, and S. Poll, "A Framework for Systematic Benchmarking of Monitoring and Diagnostic Systems," IEEE International Conference on Prognostics and Health Management, October 6-9, 2008.

Leao B.P., T. Yoneyama, G. C. Rocha, and K. T. Fitzgibbon, "Prognostics Performance Metrics and their Relation to Requirements, Design, Verification and Cost-Benefit," IEEE International Conference on Prognostics and Health Management, 2008.

Line J.K. and N. S. Clements, "Prognostics Usefulness Criteria," in IEEE Aerospace Conference, 2006.

MacConnell J.H., "ISHM \& Design: A review of the benefits of the ideal ISHM system," in IEEE Aerospace Conference, 2007.

Marz T.F., "Integrated Diagnostics: Operational Missions, Diagnostic Types, Characteristics, and Capability Gaps," 2005.

Millar R.C., "A Systems Engineering Approach to PHM for Military Aircraft Propulsion Systems," in IEEE Aerospace Conference, 2007.

KIF, "Knowledge Interchange Format, Working draft of proposed American national standard," vol. Document No. X3T2/98-004, 1998.

Nenninger G., "Aviation Condition Based Maintenance (CBM)," in DoD Maintenance Symposium $1 \&$ Exhibition, 2007.

Novis A. and H. Powrie, "PHM Sensor Implementation in the Real World - a Status Report," in IEEE Aerospace Conference, 2006.

Ofsthun S., "Integrated Vehicle Health Management for Aerospace Platforms," IEEE Instrumentation \& Measurement Magazine, pp. 21-24, September, 2002 2002.

Pritchett A.R., B. Vandor, and K. Edwards, "Testing and Implementing cockpit Alerting systems," in Reliability Engineering and System Safety. vol. 75, 2002, pp. 193-206.
Saxena A., J. Celaya, E. Balaban, K. Goebel, B. Saha, S. Saha, and M. Schwabacher, "Metrics for Evaluating Performance of Prognostic Techniques," IEEE International Conference on Prognostics and Health Management, October 6-9, 2008

Scandura P.A., "Integrated Vehicle health Management as a System Engineering Discipline," in The 24th Digital Avionics Systems Conference. vol. 2, 2005.

Sheppard J..W. and T. J. Wilmering, "Recent Advances in IEEE Standards for Diagnosis and Diagnostic Maturation," in IEEE Aerospace Conference, 2006.

Sheppard J.W. and M. A. Kaufman, "IEEE Information Modeling Standards for Test and Diagnosis," in 5th Annual Joint Aerospace Weapon System Support, Sensors and Simulation Symposium San Diego, CA, 1999.

Song L. and J. K. Kuchar, "Dissonance Between Multiple Alerting Systems Part I: Modeling and Analysis," in IEEE Transactions on Systems, man, and Cybernetics-Part A: Systems and Humans. vol. 33, 2003.

Vincent B. and A. R. Pritchett, "Requirements Specification for Health Monitoring Systems Capable of Resolving flight Control System Faults," in The 20th Conference Digital Avionics Systems. vol. 1, 2001, pp. 3D4/1 3D4/8.

Westervelt K., "Fixing BIT on the V-22 Osprey," IEEE Aerospace Conference, March, 2006.

Wilmering T.J., "When Good Diagnostics Go Bad Why Maturation is Still Hard," in IEEE Aerospace Conference. vol. 7, 2003, pp. 31373147.

Yukish M., C. Byington, and R. Campbell, "Issues in the Design and Optimization of Health Management Systems," in New Frontiers in Integrated Diagnostics and Prognostics, Proceedings of the 55th Meeting of the Society for Machinery Failure Prevention Technology Virginia Beach, Virginia, 2001.

Zhang S., R. Kang, X. He, and M. G. Pecht, "China's Efforts in Prognostics and Health Management," in IEEE Transactions on Components and Packaging Technologies. vol. 31, 2008. 
Kevin R. Wheeler received the B.S. and M.S. degrees from the University of New Hampshire, Durham, in 1988 and 1991, respectively, and the Ph.D. degree from the University of Cincinnati, Cincinnati, OH, in 1996, all in electrical engineering. After graduation, he joined the IBM Almaden Research Center to develop web-mining algorithms. In 1997, he joined the Computational Sciences Division, NASA Ames Research Center, Moffett Field, CA. His research interests include applying probability theory to automating problems in integrated vehicle health management, the Earth sciences, man-machine interfaces, and robotics.

Tolga Kurtoglu is a Research Scientist with Palo Alto Research Center in the Embedded Reasoning Area. His research focuses on the development of prognostic and health management systems, model-based diagnosis, design automation and optimization, and risk and reliability based design. He received his Ph.D. in Mechanical Engineering from the University of Texas at Austin in 2007 and has an M.S. degree in the same field from Carnegie Mellon University. Dr. Kurtoglu has published over 40 articles and papers in various journals and conferences and is an active member of ASME, ASEE, AIAA, and AAAI. Prior to his work with PARC, he worked at MCT/NASA Ames Research Center as a research scientist and at Dell Corporation as a design engineer.

Scott Poll is a Research Engineer with the National Aeronautics and Space Administration (NASA) Ames Research Center, Moffett Field, CA, where he is the deputy lead for the Diagnostics and Prognostics Group in the Intelligent Systems Division. $\mathrm{He}$ is co-leading the evolution of a laboratory designed to enable the development, maturation, and benchmarking of diagnostic, prognostic, and decision technologies for system health management applications. He was previously the Associate Principal Investigator for Prognostics in the Integrated Vehicle Health Management Project in NASA's Aviation Safety Program. He received the BSE degree in Aerospace Engineering from the University of Michigan in 1994, and the MS degree in Aeronautical Engineering from the California Institute of Technology in 1995. 